\section{Influence of Angiotensin-Converting Enzyme Inhibitors on Hypotension after Anesthetic Induction. Is the Preoperative Discontinuation of this Drug Necessary?}

Verônica Vieira da Costa, M.D., Alexandre Curvelo Caldas, M.D., Luiz Guilherme Nadal Nunes, M.D., Paulo Sérgio Siebra Beraldo, M.D., Renato Ângelo Saraiva, M.D.

\section{INTRODUCTION}

The renin-angiotensin-aldosterone system (RAAS) is one of the systems responsible for pressure levels and, therefore, it is an important target in the treatment of hypertension ${ }^{1}$. Production of angiotensin II, which exerts its effects on the angiotensin receptor, is the final RAAS pathway. When activated the receptor triggers aldosterone secretion, peripheral vasoconstriction, proliferation of cardiac muscle cells, and it also degrades brabykinin, a systemic vasodilator. The use of angiotensin-converting enzyme inhibitors (ACE inhibitors) is one of the means available to block this system ${ }^{1}$. Besides being the first line treatment of hypertension, those drugs also decrease morbidity and mortality in patients with heart failure, acute myocardial infarction, especially in patients with low ejection fraction, and they are also useful on the secondary prevention of strokes ${ }^{2}$. Patients recovering from unstable angina or acute myocardial infarction without elevation of the ST segment and who have concomitant hypertension, diabetes mellitus, or heart failure represent another group that seems to benefit from the continuous use of ACE inhibitors ${ }^{3,4}$.

Therefore, the indication of this class of drugs in patients with hypertension has been well-defined. Maintenance or discontinuation of this type of drug on the day of the anesthesia and surgical procedure is controversial.

Preoperative maintenance of drugs, such as beta-blockers and $\alpha 2$-agonists ${ }^{5,6}$ to protect the myocardium during the surgery, and drugs whose preoperative discontinuation can cause rebound hypertension such as $\alpha 2$-agonists is re- commended ${ }^{7}$. In contrast, the discontinuation of drugs, such as angiotensin-converting enzyme inhibitors (ACE inhibitors) on the day of the surgery based on reports of significant hypotension after induction of anesthesia suggesting a deleterious interaction between ACE inhibitors and anesthetics in general has been questioned or suggested by some authors ${ }^{8,9}$.

However, discontinuation of drugs used for a long time, such as antihypertensives, can implicate on a higher risk of intraoperative hypertensive peaks with harmful consequences for the patient ${ }^{7}$. This has generated controversies among anesthesiologists and, occasionally, conflicts with the physician in charge.

The objective of this preliminary study was to evaluate the influence of the preoperative use of ACE inhibitors on the incidence of clinically significant hypotension (hypotension requiring intervention by the anesthesiologist) after anesthetic induction.

\section{METHODS}

After approval by the Ethics Committee of the hospital, a case-control, retrospective study in which the study group was composed by all patients who presented significant hypotension after anesthetic induction during the study period, i.e., one year, was undertaken. Cases of hypotension that required intervention such a volume expansion and use of vasopressors by the anesthesiologist responsible for the case were considered significant.

Patients underwent orthopedic, neurosurgical, reconstructive plastic surgery, urologic, and thoracic procedures.

Electronic medical records were reviewed for data on anesthetic induction, the moment the patient developed hypotension, therapeutic measures, and evolution of the case.

The control group was composed by four patients, randomly selected, for each study patient, to increase the power of the statistical analysis ${ }^{10}$.

Patients in the control group were in the same age range, underwent the same type of surgery and at the same time as the study patients, and did not develop hypotension after anesthetic induction. Patients younger than 18 years and those who received local anesthetics or sedation as the only technique were excluded from the study.

Parameters analyzed were as follows: age, gender, size of the surgery, prior diagnosis of hypertension, use of ACE inhibitors, physical status (ASA), intraoperative bleeding, anesthetic technique, and duration of the surgery.

Analysis of Variance was used for numerical parameters and Fisher's Exact test for categorical parameters. For categorical parameters with significant association, the degree of increase in risk was determined by odds ratio. Univariate and multiple analyses were also undertaken using logistic regressions. Data were processed by SPSS for Windows, version 13.0 . 


\section{RESULTS}

Two thousand one hundred and seventy-nine anesthesia records were analyzed. Forty patient developed significant hypotension and were included in the study group. This configures a prevalence of $1.83(95 \% \mathrm{Cl} 1.3$ to 2.5$)$ episodes of hypotension for 100 surgical procedures. One hundred and seventy one patients were included in the control group.

As for demographic characteristics, the mean age of patients in the study group was higher than that of the control group $(p<0.001)$ (Table I).

Both groups did not differ regarding gender.

Twenty (50\%) out of 40 patients in the study group had hypertension. This incidence was lower in the control group, in which only 31 patients had hypertension $(18.1 \%$; $p<$ 0.001 ).

In the study group, eight patients used ACE inhibitors on the day of the surgery. Six patients were taking captopril, one enalapril, and one vasopril plus. In the majority of those patients, ACE inhibitors were associated with other drugs, such as diuretics, beta blockers, and calcium channel blockers. Only two patients were using only ACE inhibitors for control of hypertension. In the remaining 12 hypertensive patients who did not use ACE inhibitors, hypertension was treated with other types of drugs (Table I).
In the control group, 31 patients had hypertension; 10 of those patients took ACE inhibitors on the day of the surgery. Five patients used captopril, four enalapril, and one patient used lisinopril. The remaining 21 hypertensive patients in this group were taking other class of anti-hypertensive drugs (Table I).

As for the size of the surgery, 22 patients (55\%) in the study group underwent major surgeries, while minor surgeries predominated in the control group $(p<0.05)$.

Physical status (ASA) was also different in both groups. Only $5(12.5 \%)$ patients in the study group were classified as ASA I, compared to 60 (34.7\%) patients in the control group ( $p<$ 0.05).

Thirty-one (77.5\%) patients in the study group had other associated diseases, such as diabetes mellitus, hypothyroidism, and cardiopathies, associated or not with hypertension. Only nine patients in this group did not have other diseases than that responsible for the surgical indication.

As for the moment during anesthesia in which patients developed hypotension, 25 patients in the study group developed hypotension during anesthetic induction. Four of them also had hypotension during maintenance of anesthesia. In one patient, this information was not recorded in the medical record.

Patients underwent different anesthetic techniques. In the study group, 28 patients underwent general anesthesia, and

Table I - Basic Characteristics of the Patients in the Study and Control Groups

\begin{tabular}{|c|c|c|c|c|}
\hline \multirow[b]{2}{*}{ Characteristics } & \multicolumn{2}{|c|}{ Patients } & \multirow[b]{2}{*}{ OR (Cl95) } & \multirow[b]{2}{*}{$p$} \\
\hline & Cases $(n=40)$ & Control $(n=171$ & & \\
\hline Age & $62.0 \pm 13.6$ & $44.9 \pm 15.9$ & & $<0.001$ ** \\
\hline Gender (M/F) & $20 / 20$ & $96 / 77$ & & NS \\
\hline HTN (Yes/No) & $20 / 20$ & $31 / 142$ & $4.58(2.20-9.52)$ & $<0.001$ * \\
\hline \multicolumn{5}{|c|}{ Physical Status (ASA) greater than 1} \\
\hline (Yes/No) & $35 / 5$ & $113 / 60$ & $3.72(1.38-9.98)$ & $<0.05^{*}$ \\
\hline General anesthesia & $27 / 13$ & $139 / 35$ & & NS \\
\hline \multicolumn{5}{|c|}{ General anesthesia with peripheral block } \\
\hline (Yes/No) & $14 / 26$ & $37 / 136$ & & NS \\
\hline \multicolumn{5}{|c|}{ ACEls on the day of the surgery } \\
\hline (Yes/No) & $8 / 32$ & $11 / 162$ & $3.68(1.37-9.87)$ & $<0.05^{*}$ \\
\hline \multicolumn{5}{|c|}{ Considerable and severe bleeding } \\
\hline (Yes/No) & $12 / 28$ & $26 / 147$ & $2.42(1.10-5.36)$ & $<0.05^{*}$ \\
\hline
\end{tabular}

$\mathrm{OR}=$ odds ratio; $\mathrm{Cl} 95=95 \%$ confidence interval; $\mathrm{HTN}=$ hypertension

$\mathrm{NS}=$ non significant; ${ }^{*}=$ ANOVA; ${ }^{*}=$ Fisher's exact test 
Table II - Results of the Multiple Logistic Regression Model Forward Stepwise

\begin{tabular}{lccc}
\hline Parameters & SE & $p$ & OR (Cl95) \\
\hline Age & 0.013 & $<0.001$ & $1.071(1.044-1.098)$ \\
$\begin{array}{c}\text { Size of the } \\
\text { surgery }\end{array}$ & 0.393 & $<0.035$ & $2.306(1.067-4.982)$ \\
\hline
\end{tabular}

$\mathrm{SE}=$ standard error $; \mathrm{OR}=$ odds ratio $; \mathrm{Cl} 95=95 \%$ confidence interval

in 11 of them it was associated with regional blocks. Twelve patients underwent regional blocks associated with intravenous sedation. One hundred and thirty-eight patients in the control group underwent general anesthesia, and in 72 of them it was associated with regional blocks. Thirty five patients underwent regional blocks associated with intravenous sedation.

Univariate analysis showed an association between hypotension after anesthetic induction and the following parameters: advanced age $(p<0.001)$, prior diagnosis of hypertension ( $p$ $<0.001)$, ACEls $(p=0.006)$, physical status (ASA) $(p=0.006)$, and the size of the surgery $(p=0.028)$.

Stratified analysis including only patients with a diagnosis of hypertension did not show an association of hypotension and ACE inhibitors.

Logistic regression (multiple) (Table II) analysis maintained the association of hypotension and the size of the surgery (odds ratio $=1.07 ; 95 \% \mathrm{Cl}, 1.04-1.10$ ) and age (odds ratio: $2.31 ; 95 \% \mathrm{Cl}, 1.07-4.98)$. The use of ACE inhibitors was associated with advanced age $(p<0.001)$.

\section{DISCUSSION}

From September 2006 to July 2007 a group of patients who developed hypotension during anesthesia requiring intervention by the anesthesiologist was evaluated. This group included patients of both genders, mean age of 62 years, and $50 \%$ of them had a prior diagnosis of hypertension. Those patients developed hypotension after anesthetic induction and when the use of ACE inhibitors was analyzed as an isolated parameter, it represented a risk factor for the development of hypotension. However, in the presence of other parameters, such as the age of the patient and size of the surgery the use of ACE inhibitors was not a dominant risk factor.

Considering the result of multiple analysis and the association of ACE inhibitors and age, it is possible that the use of ACE inhibitors was significant in the univariate analysis as a function of its association with advanced age. The incidence of hypertension was probably higher in older patients in whom hypertension is more common and, consequently, the use of these drugs more common.

It has been reported in the literature that patients undergoing general anesthesia who took ACE inhibitors up to 10 hours before anesthetic induction have an independent risk factor for the development of hypotension up to 30 minutes after induction, and this hypotension was considered moderate by the authors (systolic pressure between 85 and $65 \mathrm{mmHg}{ }^{11}$. However, this hypotension responded to conventional treatment without further consequences for the patient. An association between age and the development of hypotension was not observed. The authors did not generalize the discontinuation of this drug on the day of the surgery; however, they suggest caution especially in patients who might develop complications after the hypotensive episode such as those with severe aortic stenosis or critical cerebrovascular disease ${ }^{11}$. This study had some methodological limitations that might compromise its internal validity. It was not a controlled study and the authors also included angiotensin II receptor antagonists, and the attending physician decided whether or not to discontinue the medication on the day of the surgery, without random distribution. It is possible that patients whose medication was discontinued were more likely to develop hypotension by other causes like associated diseases. Hypotension might have been underestimated, since some anesthesiologists administered volume and vasopressors before the development of clinically relevant hypotension, which represents another limitation of this study. In the present study, all patients who developed hypotension requiring intervention during anesthesia under treatment or not with ACE inhibitors over a 10-month period were evaluated. Those patients underwent different anesthetic techniques and patients randomly chosen among 2,179 procedures, including those treated with ACE inhibitors who did not develop hypotension, were included in the control group. It was demonstrated that other factors associated with the use of ACE inhibitors may be more significant, but were not considered in the above mentioned study.

Another prospective study evaluated the influence of the chronic use of ACE inhibitors on the development of hypotension after anesthetic induction for peripheral vascular surgeries. The authors concluded that ACE inhibitors influenced, indeed, the development of hypotension approximately 30 minutes after anesthetic induction, and the reduction in blood pressure is more significant in patients on chronic treatment with enalapril ${ }^{9}$. The authors did not observe differences in the age of patients in the study groups, whose mean age was $67 \pm 5$ years. They also emphasized that although cardiac events were not observed $20 \%$ of the patients whose ACE inhibitor was discontinued developed hypertension (systolic pressure greater than $180 \mathrm{mmHg}$ ), but they did not consider this incidence important. They also observed that when these drugs were maintained until the day of the surgery, the incidence of hypotension after anesthetic induction in hypertensive patients was elevated $(64 \%-100 \%)^{9}$. Although the magnitude of the reduction in blood pressure did not show a correlation with the reduction in the plasma activity of the converting enzyme, the incidence of hypotension after anesthetic induction was reduced $(<20 \%)$ when the plasma 
activity of the enzyme was restored by discontinuing the drug on the day of the surgery ${ }^{9}$. In this study, the degree of hypotension considered was quantitative, and not clinical, which might have influenced the results. It also offered little information on how maintenance of those drugs may affect current clinical practice and how other factors that were not controlled in the study, such as the concomitant use of other anti-hypertensive drugs, may influence the results. The hydration status, which is extremely important in hypertensive patients, was not reported. Those facts justify the difference between their results and ours.

In the current study, patients who developed hypotension (study group) had been fasting for 10 to 12 hours, and it is possible that, on that occasion, they presented some degree of dehydration. However, hypotension was considered relevant when it required the intervention of the anesthesiologist, and not only the numeric value. Another difference is that all types of ACE inhibitors were included, but most patients used captopril, which was mentioned by the authors as the one that favors the least the development of hypotension ${ }^{9}$. This could also have contributed for the differences between the results of both studies.

After logistic regression, the age of the patient and the size of the surgery maintained the association with the development of hypotension after anesthetic induction. Initially, the analysis (univariate analysis) indicated that the use of ACEls was determinant for the development of hypotension after induction, but in the presence of other parameters (logistic regression analysis) the use of ACE inhibitors was no longer the most important risk factor. In fact, in the present study advanced age and the classification of surgery were the risk factors that determined the development of hypotension after anesthetic induction. It was demonstrated that the use of ACE inhibitors was associated with advanced age, i.e., in the present study older patients were the ones who used ACE inhibitors, which might cause confusion.

Another study that also used univariate, stratified, and logistic regression analysis to determine predictive factors of hypotension after anesthetic induction did not observe an association between the preoperative use of these drugs and hypotension ${ }^{12}$. We agree with the authors and reinforce the power of this type of statistical analysis on the determination of risk factors.

Regarding intraoperative hypotension and its repercussion in other organ systems, some authors have recommended continuation of the treatment with ACE inhibitors for several reasons. Some authors suggest that the uninterrupted use of those drugs can be associated with a reduction in myocardial ischemia in cardiac surgeries ${ }^{13}$. On the other hand, other authors observed that, during cardiopulmonary bypass, the effective renal flow and glomerular filtration rate remain unchanged, while sodium excretion was greater in patients who received captopril when compared with patients who received placebo ${ }^{13}$. Others argue that not one single study assessed the potential level of protection of maintaining the treatment with ACE inhibitors in patients at high risk for the development of renal failure ${ }^{11}$. Those authors believe that the preoperative maintenance of angiotensin II-converting enzyme inhibitors and angiotensin receptor antagonists deserves further studies with a larger patient population and with different risk factors to guarantee the risk-benefit offered by those treatments.

Note that in the present study, since it included a more heterogeneous population, patients were not divided in chronic and acute users of ACE inhibitors. It has been well defined in the literature that parasympathetic activity is increased after the chronic use of ACE inhibitors when compared with the acute use of this drug ${ }^{14}$. Its isolated use has not been assessed as well, and it has been reported that its association with other anti-hypertensive drugs is common in patients with moderate to severe hypertension that might hinder blood pressure regulation during anesthesia ${ }^{14}$. In the present study, only three patients used ACE inhibitors alone. Maybe the methodology including also cases of acute use might justify the low prevalence observed in this study, only 1.8 episodes of hypotension for 100 surgical interventions. Similarly, it is possible that the development of hypotension after anesthetic induction in the study group was secondary to the association of ACE inhibitors with other anti-hypertensive drugs and not only to the use of ACE inhibitors, since those patients were not evaluated in different groups.

The RAAS is responsible not only for the regulation of the volume of the extracellular fluid, but it is also an important regulator of the venous return and blood pressure during acute hemodynamic stress. Those effects can be considered when other factors interfere with cardiovascular homeostasis and therefore deterioration of hemodynamic parameters can be observed when the intravascular volume is decreased ${ }^{14}$. The same authors suggested as a temporary solution the preoperative discontinuation of the medication in patients with other predisposing factors such as severe hypertension, risk of hypovolemia, and left ventricular diastolic dysfunction. Maintaining those drugs and a satisfactory intravascular volume during anesthesia could be another solution. Anyway, they state that hypertensive patients can develop hypotension after anesthetic induction, whether the drug is discontinued or not, but in most cases (> 75\%) it can be treated with the administration of sympathetic agonists, such as ephedrine and phenylephrine. In those patients with resistant hypotension, vasopressin can be effective ${ }^{14}$.

Another prospective study evaluated patients undergoing subarachnoid block for orthopedic and urologic procedures, and repair of inguinal hernia. The authors evaluated a group of patients treated with ACE inhibitors for at least four weeks prior to the surgery and compared them with a group of patients who had never taken those drugs, approximately 20 minutes after the subarachnoid block. An increase in the reduction of the blood pressure was not observed in the group of patients treated with ACE inhibitors during the observation period when compared to the other patients. They also 
observed that the levels of vasopressin were elevated and those of angiotensin II were low in patients treated with ACE inhibitors while in those who were not taking those drugs the levels of vasopressin did not rise suggesting that hypotension was compensated by different mechanisms ${ }^{15}$.

In the present study all types of anesthesia were included except local anesthesia and sedation. It is possible that this compensatory mechanism was present in some cases and for this reason not all patients treated with ACE inhibitors developed hypotension.

Another prospective study evaluated two groups of patients undergoing cardiac surgeries. One group (random distribution) did not take the medication on the day of the surgery while the other group used ACE inhibitors on that day. The anesthetic technique was standardized; fentanyl and ethomidate were used for induction, and pancuronium was used for the neuromuscular blockade. Halothane was used for anesthesia maintenance. Hypotension was defined as systolic pressure below $85 \mathrm{mmHg}$. The results showed that the group of patients who did not take the medication required less vasoconstrictor agents than the group of patients who took the medication; however, the second group required more vasodilator during the postoperative period to control the blood pressure. The authors concluded that the discontinuation of ACE inhibitors on the day of the surgery has some effects on the hemodynamic control of patients during the procedure, but the advantages are not enough to recommend the routine discontinuation of these drugs ${ }^{16}$.

Patients in the study group had transitory hypotension that was promptly reversed with hydration and in most cases single dose of vasoconstrictor agents. In agreement with the authors mentioned above, there are no reasons to justify the recommendation of routine discontinuation of ACE inhibitors, especially when facing the risk of having to use vasodilators in the immediate postoperative period.

Angiotensin-converting enzyme inhibitors have been widely used in the treatment of heart failure ${ }^{8}$. Based on reports of hypotension during anesthetic induction, the authors proposed to evaluate the hemodynamic effects of anesthesia on the incidence of significant hypotension after induction of anesthesia in patients treated with ACE inhibitors (50\% of the patients) and those not treated with those drugs for ventricular diastolic dysfunction after myocardial infarction. Hypotension was defined as mean arterial pressure lower than $70 \mathrm{mmHg}$. A reduction in blood pressure and heart rate was observed in both groups, but a significantly higher reduction in the cardiac index was observed in patients treated with ACE inhibitors although peripheral vascular resistance did not change. The authors concluded that despite the hemodynamic effects of anesthesia induction in patients with left ventricular dysfunction were modified by the chronic use of ACE inhibitors the incidence of severe hypotension was not higher in the group of patients who used those drugs on the day of the surgery ${ }^{8}$. Although the methodology of that study was different than that of the present study, a cause-effect relationship between the use of ACE inhibitors on the day of the surgery and an increase in the incidence of hypotension after induction of anesthesia was also not observed.

For the reasons discussed earlier, inhibition of the autonomous nervous system (ANS) induced by anesthesia and prior blockade of the RAAS can cause hypotension. But whether this affects all hypertensive patients treated with ACE inhibitors, therefore justifying the preoperative discontinuation of the medication, or it is related with the presence of other factors associated with the use of ACE inhibitors is not clear. Based on preliminary results, when the use of these drugs is associated with other factors, such as advanced age and size of the surgery, those other factors have greater influence on the development of hypotension after anesthetic induction. The Brazilian Society of Cardiology published recently guidelines for perioperative evaluation and recommends that all anti-hypertensive drugs (including ACE inhibitors) should be continued in the preoperative period including the day of surgery. The is a consensus over this recommendation, and the level of evidence is based on consensus publications and opinion of specialists ${ }^{2}$.

The present study has some limitations, such as the retrospective nature, i.e., search of electronic patient records. One cannot firmly state that hypotension developed right after anesthetic induction or at the beginning of anesthetic maintenance, although anesthetic records showed the moment the patient developed hypotension. However, the difficulties to gather information are inherent to retrospective studies. The majority of patients treated with ACE inhibitors used captopril that has a shorter half-life, and one cannot indicate accurately the interval between the administration of the drug and anesthetic induction. Lastly, the criteria for intervention, such as the administration of vasopressors and fluids, were individual. In the present study, it was demonstrated that the use of ACE inhibitors in the presence of other factors is not an independent factor for the development of hypotension after anesthetic induction. The study included a control group with the same clinical characteristics as those of the study group, including the regular use of ACE inhibitors.

The association between the preoperative use of ACE inhibitors and clinically relevant hypotension after anesthetic induction was not clear; therefore, ACE inhibitors do not seem to influence the development of hypotension after anesthetic induction. Based on those results, we considered that the recommendation to routinely discontinue ACE inhibitors on the day of surgery should be reviewed. Other studies should be undertaken to confirm those results.

\section{REFERÊNCIAS - REFERENCES}

01. Victor R - Arterial Hypertension, em: Goldman L, Ausiello D - Cecil Textbook of Medicine, $22^{\text {th }}$ Ed, Philadelphia, Elsevier, 2004;JA346363. 
02. Sociedade Brasileira de Cardiologia - Diretrizes de Hipertensão Arterial, 5., São Paulo: 2006. Disponível em <http://publicacoes. cardiol.br/consenso/2006/VDiretriz-HA.pdf>. Acesso em 22/ ago/2007.

03. Yusuf S, Sleight P, Poque J et al. - Effect of an angiotensinconverting-enzyme inhibitor, ramipril, on cardiovascular events in high-risk patients. New England J Med, 2000;342:145-153.

04. Anderson JL, Adams CD, Antman EM et al. - ACC/AHA 2007 guidelines for the management of patients with unstable angina/ non-ST-elevation myocardial infarction: a report of the American College of Cardiology/American Heart Association Task Force on Practice Guidelines. J Am Coll Cardiol, 2007;50:e1-e157.

05. Wallace A, Layug B, Tateo I et al. - Prophylactic atenolol reduces postoperative myocardial ischemia: McSPI Research Group. Anesthesiology, 1998;88:7-17.

06. Stevens RD, Burri H, Tramer MR - Pharmacologic myocardial protection in patients undergoing noncardiac surgery: a quantitative systematic review. Anesth Analg, 2003;97:623-633.

07. Schmidt GR, Schuna AA - Rebound hypertension after discontinuation of transdermal clonidine. Clin Pharm, 1988;7:772-774.

08. Ryckwaert F, Colson P - Hemodynamic effects of anesthesia in patients with ischemic heart failure chronically treated with angiotensin-converting inhibitors. Anesth Analg, 1997;84:945-949.

09. Coriat P, Richer C, Douraki T et al. - Influence of chronic angiotensin-converting enzyme inhibition on anesthetic induction. Anesthesiology, 1994;81:299-307.

10. Grimes DA, Schulz KF - Compared to what? Finding controls for case-controls studies. Lancet, 2005;365:1429-1433.

11. Comfere T, Sprung J, Kumar MM et al. - Angiotensin system inhibitors in a general surgical population. Anesth Analg, 2005; 100:636-644.

12. Reich DL, Hossain S, Krol M et al. - Predictors of hypotension after induction of general anesthesia. Anesth Analg, 2005;101: 622-628.

13. Colson P, Ribstein J, Mimran A - Effect of angiotensin converting enzyme inhibition on blood pressure and renal function during open heart surgery. Anesthesiology, 1990;72:23-27.

14. Colson $P$, Ryckwaert $F$, Coriat $P$ - Renin angiotensin system antagonists and anesthesia. Anest Analg, 1999;89:1143-1155.

15. Hohne C, Meier L, Boewke W et al. - ACE inhibition does not exaggerate the blood pressure decrease in the early phase of spinal anaesthesia. Acta Anaesthesiol Scand, 2003;47:891-896.

16. Pigott DW, Nagle $C$, Allman $K$ et al. - Effect of omitting regular ACE inhibitor medication before cardiac surgery on haemodynamic variables and vasoactive drug requirements. $\mathrm{Br} J$ Anaesth, 1999;83:715-720.

\section{RESUMEN}

Costa VV, Caldas AC, Nunes LGN, Beraldo PSS, Saraiva RA - Influencia del Uso Crónico de los Inhibidores de la Enzima Conversora de la Angiotensina en la Hipotensión Arterial después de la Inducción Anestésica. ¿Es Necesario Suspender Ese Fármaco en el Preoperatorio?

JUSTIFICATIVA Y OBJETIVOS: En base a relatos de hipotensión arterial durante la anestesia, se ha sugerido la suspensión de medicamentos como los inhibidores de la enzima conversora de angiotensina (IECA). Eso puede redundar en un riesgo más elevado de picos hipertensivos en el intraoperatorio y con efectos perjudiciales para el paciente. El objetivo de este estudio, fue evaluar la influencia de los IECA utilizados en el preoperatorio si surge la hipotensión arterial durante la anestesia.

MÉTODO: Delineamiento de tipo caso control, donde los casos fueron pacientes que presentaron hipotensión arterial después de la inducción de la anestesia. Como controles fueron seleccionados pacientes de la misma franja etaria y sexo, sometidos a la intervención quirúrgica en el mismo período de los casos y que no presentaron hipotensión arterial. Las variables de interés fueron las siguientes: edad, sexo, porte quirúrgico, diagnóstico previo de hipertensión arterial sistémica (HAS), uso de IECA, estado físico (ASA), sangramiento en el intraoperatorio, técnica anestésica y tiempo quirúrgico.

RESULTADOS: Cuarenta pacientes presentaron hipotensión arterial, en un total de 2.179 operaciones. De ellos, 20 usaron IECA el día de la operación. El grupo control estuvo compuesto por 171 pacientes, de los cuales 11 usaron IECA. En el análisis univariado, se encontró una asociación entre la hipotensión arterial y la edad avanzada $(p<0,001)$, diagnóstico previo de hipertensión arterial ( $p$ $<0,001)$, uso de IECA $(p=0,006)$, estado físico del paciente (ASA) $(p=0,006)$ y porte quirúrgico $(p=0,028)$. En un análisis estratificado, no hubo asociación de la hipotensión arterial con el uso de IECA. En la regresión logística, se mantuvieron la asociación con la hipotensión arterial, el porte quirúrgico y la edad del paciente.

CONCLUSIONES: No encontramos asociación del uso de IECA e hipotensión arterial durante la anestesia. Los autores consideraron que la orientación de suspender el IECA en la víspera de la intervención quirúrgica tiene que ser analizada nuevamente. Otros estudios deben ser considerados para confirmar ese resultado. 